\title{
Combined effects of maternal inflammation and neonatal hyperoxia on lung fibrosis and RAGE expression in newborn rats
}

\author{
Chien-Ling Su' ${ }^{1}$ Hsiu-Chu Chou ${ }^{2}$, Liang-Ti Huang ${ }^{3}$, Tsu-Fu Yeh ${ }^{4}$ and Chung-Ming Chen ${ }^{4-6}$
}

BACKGROUND: Receptors for advanced glycation end products (RAGE) have been implicated in fibrotic processes. We hypothesized that lung fibrosis induced by maternal lipopolysaccharide (LPS)-mediated inflammation and neonatal hyperoxia involves RAGE in newborn rats.

METHODS: Pregnant Sprague-Dawley rats received intraperitoneal injections of LPS or normal saline (NS) on 20 and $21 \mathrm{~d}$ of gestation. The pups were reared in room air (RA) or an $\mathrm{O}_{2}-$ enrich atmosphere $\left(\mathrm{O}_{2}\right)$, creating the four study groups, NS + $R A$, NS $+\mathrm{O}_{2}$, LPS + RA, and LPS $+\mathrm{O}_{2}$. The $\mathrm{O}_{2}$ treatment was $>95 \% \mathrm{O}_{2}$ for $7 \mathrm{~d}$, followed by $60 \% \mathrm{O}_{2}$ for $14 \mathrm{~d}$.

RESULTS: Rat pups born to LPS-injected dams exhibited significantly higher lung interferon- $\gamma$ and interleukin-1 $\beta$ (IL-1 $\beta$ ) on postnatal day 7 than the pups born to NS-injected dams. Rat pups reared in hyperoxia expressed higher lung IL-10 on postnatal day 7, compared with the RA-reared pups. The LPS $+\mathrm{O}_{2}$ group had significantly higher total collagen and transforming growth factor- $\beta 1$ on postnatal days 7 and 21 than the NS+RA group. RAGE mRNA and sRAGE protein expression were significantly lower in the LPS $+\mathrm{O}_{2}$ group on postnatal day 7 than the NS+RA group.

CONCLUSION: RAGE may be involved in the pathogenesis of lung fibrosis induced by maternal systemic inflammation and postnatal hyperoxia in rat neonates.

$S^{4}$ upplemental oxygen administered to newborn infants with respiratory disorders can increase oxidative stress and lead to lung injury. Lung injury resolves with fibrosis that is prominent in larger infants who developed bronchopulmonary dysplasia (BPD) after prolonged exposure to oxygen and mechanical ventilation $(1,2)$. Prolonged exposure of neonatal mice to hyperoxic conditions resulted in decreased alveolar septation, increased terminal air space size, and increased lung fibrosis that is similar to human $\operatorname{BPD}(3,4)$.

The pathogenesis of BPD is multifactorial. Pulmonary inflammation and oxygen toxicity are believed to play important roles in the lung injury process which leads to the development of BPD (5). Epidemiological studies showed a strong association between chorioamnionitis and the development of BPD, which indicates a systemic inflammatory response during chorioamnionitis, and concluded that chorioamnionitis and inflammation are independent risk factors of BPD $(6,7)$. Intra-amniotic lipopolysaccharide (LPS) treatment amplifies the postnatal hyperoxia-induced inhibition of alveolarization, and systemic maternal inflammation and neonatal hyperoxia in series arrest alveolarization, induce lung fibrosis, and impair lung mechanics $(8,9)$.

Receptors for advanced glycation end products (RAGE) are members of the immunoglobulin superfamily of cell-surface receptors and are expressed in many cell types. The RAGE proteins are expressed at low to undetectable levels in most tissues but are most abundant in the lung (10). High levels of RAGE expression during periods of lung development suggest functionality in lung morphogenesis (11). The effect of hyperoxia on RAGE expression has been shown to differ between adult mouse and neonatal rat models $(12,13)$. Therefore, we examined the effects of prenatal systemic maternal inflammation and postnatal hyperoxia on RAGE expression in lung tissues in rat neonates.

Transforming growth factor- $\beta 1$ (TGF- $\beta 1$ ) initiates tissue repair, and its sustained production underlies the development of tissue fibrosis. In experimental models of lung fibrosis, TGF- $\beta 1$ is an important upstream effector of collagen gene expression through a variety of mechanisms, including the activation of the TGF- $\beta 1$ in the lung $(14,15)$. Li et al. suggested that hyperoxia in the developing murine lung increases TGF$\beta 1$ expression in alveolar epithelial cells and interstitial fibroblasts (16). Although TGF- $\beta 1$ has been reported to play a role in hyperoxia-induced pulmonary fibrosis (17), its relationship with RAGE expression with regard to the effects of prenatal inflammation and postnatal hyperoxia on lung tissues remains unclear.

We hypothesized that maternal LPS exposure would augment postnatal hyperoxia-induced lung fibrosis in neonatal

\footnotetext{
'School of Respiratory Therapy, College of Medicine, Taipei Medical University, Taipei, Taiwan; ${ }^{2}$ Department of Anatomy, College of Medicine, Taipei Medical University, Taipei, Taiwan; ${ }^{3}$ Department of Pediatrics, Wan Fang Hospital, Taipei Medical University, Taipei, Taiwan; ${ }^{4}$ Maternal Child Health Research Center, College of Medicine, Taipei Medical University, Taipei, Taiwan; ${ }^{5}$ Department of Pediatrics, Taipei Medical University Hospital, Taipei, Taiwan; ${ }^{6}$ Department of Pediatrics, School of Medicine, College of Medicine, Taipei Medical University, Taipei, Taiwan. Correspondence: Chung-Ming Chen (cmchen@tmu.edu.tw) 
rats. The aims of our study were to determine the effects of maternal LPS-induced inflammation and postnatal hyperoxia on lung inflammation and fibrosis in neonatal rats and to elucidate the relationship between TGF- $\beta 1$ and RAGE expression in lung fibrosis induced by maternal inflammation and hyperoxia.

\section{RESULTS}

Four normal saline (NS)-treated dams gave birth to a total of 53 pups, and 31 and 22 pups were randomly distributed to room air (RA) and hyperoxia groups, respectively. Two rat pups born to NS-treated dams and reared in hyperoxia died. Seven LPStreated dams gave birth to a total of 51 pups, and 23 and 28 pups were randomly distributed to RA and hyperoxia groups, respectively. Four and eight rat pups born to LPS-treated dams and reared in RA and hyperoxia died.

\section{Body Weight, Lung Weight, Lung to Body Weight Ratios, and Mean Linear Intercept}

The effects of maternal LPS treatment and postnatal hyperoxia on body weight, lung weight, and the lung to body weight ratio on postnatal days 7 and 21 are presented in Tables 1 and 2 . Body weights and lung weights increased from postnatal day 7 to 21 . The LPS $+\mathrm{O}_{2}$ group had significantly lower body weights on postnatal day 7 than the $\mathrm{NS}+\mathrm{RA}$ group. The $\mathrm{NS}+\mathrm{O}_{2}$ and

Table 1. Body weights, lung weights, LBWR, and MLI in rat pups born to LPS- or NS-treated mothers that were reared in normal room air or in $\mathrm{O}_{2}$-enriched air on postnatal day 7

\begin{tabular}{lccccc}
\hline Treatment & $n$ & $\begin{array}{c}\text { Body } \\
\text { weight }(g)\end{array}$ & $\begin{array}{c}\text { Lung } \\
\text { weight }(g)\end{array}$ & $\begin{array}{c}\text { LBWR } \\
(\%)\end{array}$ & $\begin{array}{c}\text { MLI } \\
(\mu \mathrm{m})\end{array}$ \\
\hline $\mathrm{NS}+\mathrm{RA}$ & 12 & $14.22 \pm 0.99$ & $0.29 \pm 0.02$ & $2.01 \pm 0.09$ & $51.03 \pm 2.92$ \\
$\mathrm{NS}+\mathrm{O}_{2}$ & 11 & $12.44 \pm 0.82$ & $0.19 \pm 0.01^{\mathrm{a}}$ & $1.57 \pm 0.06^{\mathrm{a}}$ & $58.53 \pm 5.40$ \\
$\mathrm{LPS}+\mathrm{RA}$ & 11 & $13.85 \pm 2.73$ & $0.27 \pm 0.04$ & $1.99 \pm 0.20$ & $57.89 \pm 6.32$ \\
$\mathrm{LPS}+\mathrm{O}_{2}$ & 11 & $11.26 \pm 3.34^{*}$ & $0.19 \pm 0.06^{\mathrm{a}}$ & $1.64 \pm 0.11^{\mathrm{a}}$ & $60.00 \pm 6.63^{*}$ \\
\hline
\end{tabular}

Values represent the means \pm SD.

LBWR, Lung/body weight ratio; LPS, lipopolysaccharide; MLI, mean linear intercept; NS, normal saline; $\mathrm{RA}$, room air; $\mathrm{O}_{2^{\prime}}>95 \%$ day 1 to 7 and $60 \%$ day 8 to 21 .

${ }^{*}$ Different from NS + RA group at $P<0.05$.

aifferent from NS + RA and LPS + RA groups at $P<0.001$

Table 2. Body weights, lung weights, LBWR, and MLI in rat pups born to LPS- or NS-treated mothers that were reared in normal room air or in $\mathrm{O}_{2}$-enriched air on postnatal day 21

\begin{tabular}{lccccc}
\hline Treatment & $n$ & $\begin{array}{c}\text { Body } \\
\text { weight }(\mathrm{g})\end{array}$ & $\begin{array}{c}\text { Lung } \\
\text { weight }(\mathrm{g})\end{array}$ & $\begin{array}{c}\text { LBWR } \\
(\%)\end{array}$ & $\begin{array}{c}\text { MLI } \\
(\mu \mathrm{m})\end{array}$ \\
\hline $\mathrm{NS}+\mathrm{RA}$ & 19 & $38.77 \pm 1.90$ & $0.35 \pm 0.03$ & $0.91 \pm 0.04$ & $46.66 \pm 4.96$ \\
$\mathrm{NS}+\mathrm{O}_{2}$ & 9 & $31.60 \pm 7.10$ & $0.34 \pm 0.05$ & $1.11 \pm 0.17$ & $57.64 \pm 6.63^{*}$ \\
$\mathrm{LPS}+\mathrm{RA}$ & 8 & $28.69 \pm 13.91^{*}$ & $0.35 \pm 0.07$ & $1.39 \pm 0.48^{\mathrm{a}, \mathrm{b}}$ & $55.07 \pm 7.66$ \\
$\mathrm{LPS}+\mathrm{O}_{2}$ & 9 & $30.51 \pm 7.58^{*}$ & $0.31 \pm 0.06$ & $1.04 \pm 0.12$ & $57.04 \pm 6.84^{*}$ \\
\hline
\end{tabular}

Values represent the means \pm SD.

LBWR, Lung/body weight ratio; LPS, lipopolysaccharide; MLI, mean linear intercept; NS, normal saline; $R A$, room air; $\mathrm{O}_{2^{\prime}}>95 \%$ day 1 to 7 and $60 \%$ day 8 to 21 .

*Different from NS + RA at $P<0.05$.

aifferent from NS + RA group at $P<0.001$. bifferent from LPS $+\mathrm{O}_{2}$ group at $P<0.05$.
LPS $+\mathrm{O}_{2}$ groups had significantly lower lung weights and lung to body weight ratios on postnatal day 7 , compared with the rat pups reared in normal RA. On postnatal day 21, body weights were significantly lower for the LPS + RA and LPS $+\mathrm{O}_{2}$ groups than the NS + RA group. The LPS + RA group had significantly higher lung to body weight ratios on postnatal day 21 than the NS + RA and LPS $+\mathrm{O}_{2}$ groups. The mean linear intercept decreased with advancing postnatal gestation in rat pups born to LPS- and NS-treated mothers (Tables 1 and 2). The LPS $+\mathrm{O}_{2}$ group had significantly higher mean linear intercept on postnatal days 7 and 21 than the NS + RA group.

\section{Cytokine and Chemokine Levels}

The LPS + RA and LPS $+\mathrm{O}_{2}$ groups had higher levels of interferon- $\gamma$ (IFN- $\gamma$ ), interleukin-1 $\beta$ (IL-1 $\beta$ ), and tumor necrosis factor- $\alpha$ (TNF- $\alpha$ ) in lung tissues on postnatal day 7 , compared with the NS $+\mathrm{RA}$ and $\mathrm{NS}+\mathrm{O}_{2}$ groups (Figure 1a). The differences reached statistical significance for IFN- $\gamma$ and IL-1 $\beta$. The $\mathrm{NS}+\mathrm{O}_{2}$ and LPS $+\mathrm{O}_{2}$ groups had insignificantly higher levels of IL-10 in lung tissues on postnatal day 7 than the NS + RA and LPS + RA groups. The increased levels of macrophage inflammatory protein-2 (MIP-2) and RANTES on postnatal day 7 did not reach statistical significance in any of the study groups. The levels of IFN- $\gamma$, IL-10, IL-1 $\beta$, MIP-2, RANTES, and TNF- $\alpha$ were comparable among all the study groups on postnatal day 21 (Figure $\mathbf{1 b}$ ).

\section{Total Collagen Content}

Total collagen in lung tissues increased following maternal LPS treatment and postnatal hyperoxia (Figure 2a). The LPS $+\mathrm{O}_{2}$ group had significantly higher total collagen in lung tissues on postnatal days 7 and $21\left({ }^{*} P<0.05,{ }^{\dagger} P<0.001\right.$, respectively) than the NS + RA group, and the LPS $+\mathrm{O}_{2}$ group had significantly higher total collagen in lung tissues on postnatal day 21 than the NS $+\mathrm{O}_{2}$ and LPS + RA groups $\left({ }^{\star} P<0.05\right)$.

\section{Transforming Growth Factor- $\beta 1$}

The level of TGF- $\beta 1$ in lung tissues correlated with increases in total collagen and increased after maternal LPS treatment and/ or postnatal hyperoxia (Figure $2 b$ ). The LPS $+\mathrm{O}_{2}$ group had significantly higher levels of TGF- $\beta 1$ in lung tissues on postnatal days $7\left({ }^{\dagger} P<0.001\right)$ and $21\left({ }^{*} P<0.05\right)$ than the NS + RA group.

\section{RAGE mRNA Expression}

The results of the analysis of RAGE mRNA expression in lung tissues are presented in Figure 3. The expression of RAGE mRNA decreased after maternal LPS treatment and/or postnatal hyperoxia. The LPS $+\mathrm{O}_{2}$ group had significantly lower levels of RAGE mRNA expression in lung tissues on postnatal day $7\left({ }^{*} P<0.05\right)$ than the NS + RA group.

\section{RAGE Protein Expression}

The pups that experienced postnatal hyperoxia displayed lower levels of sRAGE protein expression in lung tissues on postnatal days 7 and 21 than the pups in the NS + RA group, with the 
a
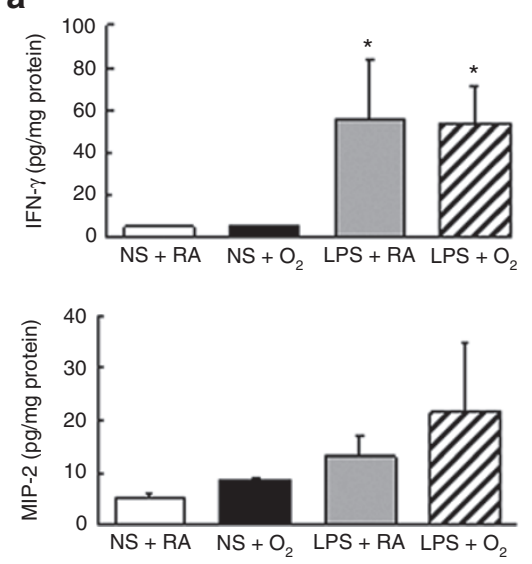

b
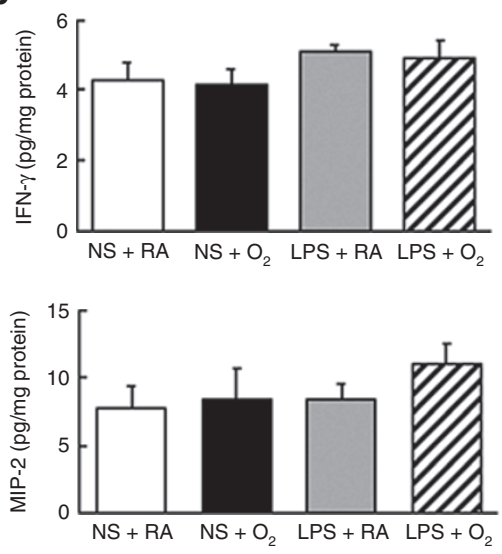
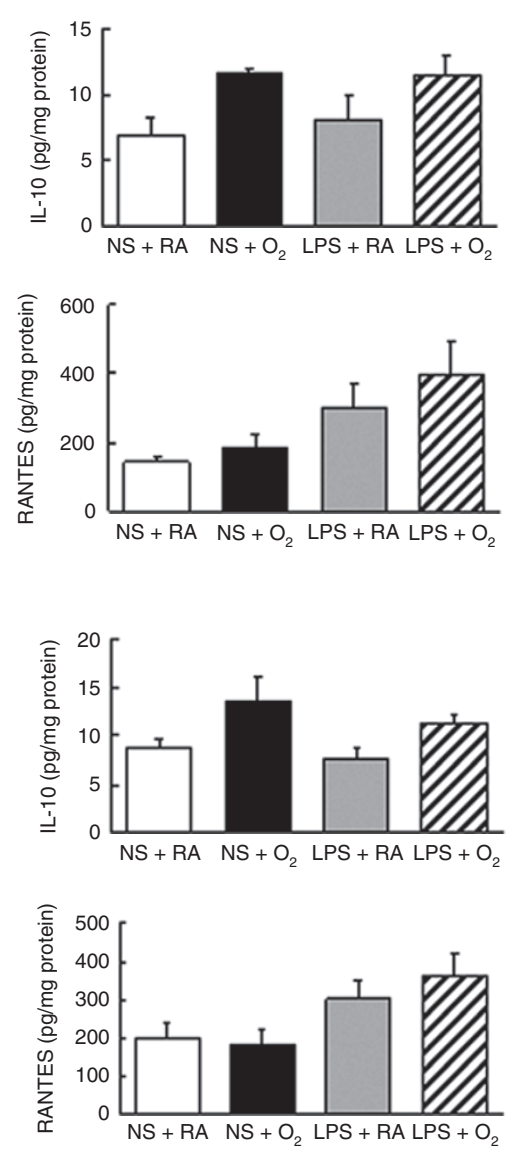
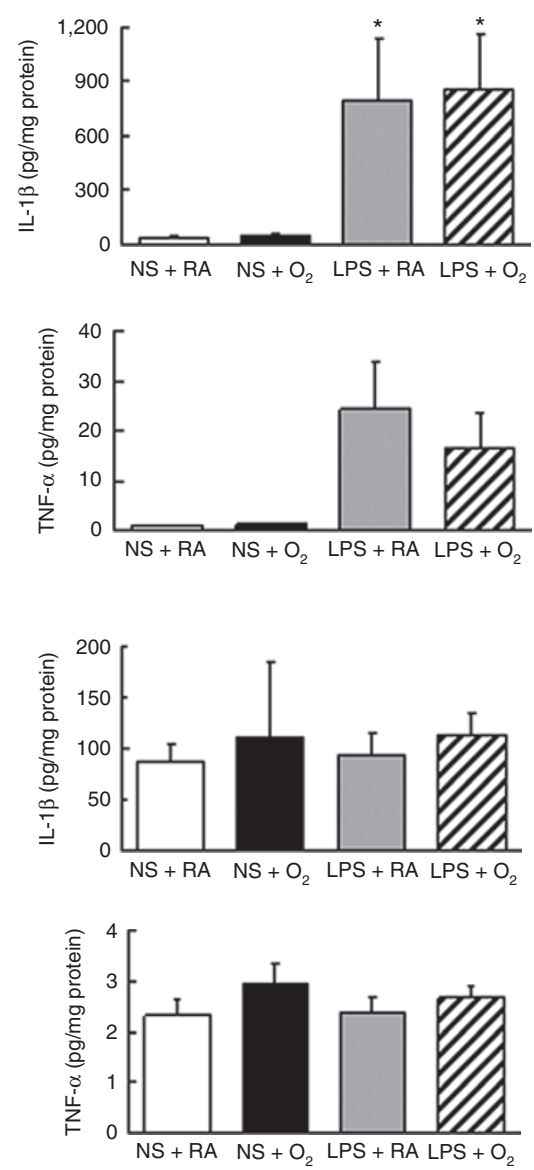

Figure 1. Lung cytokine and chemokine levels on postnatal days (a) 7 and (b) 21. (a) On postnatal day 7, rat pups born to LPS-injected dams had significantly higher levels of INF- $\gamma$ and IL-1 $\beta$ in lung tissues than the rat pups born to NS-injected dams $\left({ }^{*} P<0.05\right)$. (b) On postnatal day 21 , the levels of IFN$\gamma, \mathrm{IL}-10, \mathrm{IL}-1 \beta, \mathrm{MIP}-2, \mathrm{RANTES}$, and TNF- $\alpha$ in lung tissues were comparable among all the study groups on postnatal day 21 . NS + RA, maternal NS treatment with postnatal RA exposure (open bars); NS + $\mathrm{O}_{2}$, maternal NS treatment with postnatal $\mathrm{O}_{2}$ exposure (solid bars); LPS + RA, maternal LPS treatment with postnatal RA exposure (gray bars); and LPS $+\mathrm{O}_{2}$, maternal LPS treatment with postnatal $\mathrm{O}_{2}$ exposure (hatched bars). LPS, lipopolysaccharide; NS, normal saline; $\mathrm{O}_{2}$, hyperoxia; $\mathrm{RA}$, room air.

difference reaching statistical significance on postnatal day 7 (Figure 4a; ${ }^{*} P<0.05,{ }^{*} P<0.01$, respectively). The levels of mRAGE protein expression were comparable among all the study groups on postnatal days 7 and 21 (Figure $4 \mathbf{b}$ ).

\section{Immunofluorescence Assay}

Immunofluorescence staining of RAGE and collagen expression in lung tissues on postnatal days 7 and 21 are presented in Figure 5. The RAGE immunofluorescence was scattered in the airway epithelial cells and endothelial cells in the NS + RA group. The RAGE immunofluorescence was downregulated and collagen immunofluorescence was upregulated after maternal LPS and/or postnatal hyperoxia exposure on postnatal days 7 and 21. Collagen fluorescence was markedly increased after maternal LPS and postnatal hyperoxia exposure on postnatal days 7 and 21 .

\section{DISCUSSION}

Our in vivo model showed that maternal LPS exposure and postnatal hyperoxia increased lung inflammation, total collagen content, and TGF- $\beta 1$ expression and decreased RAGE expression in rat neonates during the first postnatal week. Prolonged exposure to a lower concentration of oxygen caused lung fibrosis, as confirmed by increased levels of total collagen and TGF- $\beta 1$ expression and decreased RAGE expression in lung tissues in the third postnatal week. The lung inflammation and collagen findings are consistent with hyperoxia-induced lung injury $(18,19)$. The major findings of our study are that the development of maternal LPS- and postnatal hyperoxiainduced lung fibrosis was associated with the decreased expression of RAGE mRNA and sRAGE protein. These results suggest that RAGE may be involved in the pathogenesis of lung fibrosis induced by maternal systemic inflammation and postnatal hyperoxia, and that the supplementation of RAGE may attenuate lung fibrosis.

In our present study, we found that rat pups exposed to maternal inflammation and/or postnatal hyperoxia exhibited lower body weights on postnatal days 7 and 21; the differences reached the level of statistical significance for LPS $+\mathrm{O}_{2}$ group on postnatal day 7 and LPS $+\mathrm{O}_{2}$ and LPS + RA groups on postnatal day 21 . These results indicated that maternal inflammation and postnatal hyperoxia displayed a trend toward 
decreased body weights in offspring. Lung weights were comparable among all of the study groups on postnatal day 21 . In the LPS + RA group, the loss of body weight was relatively greater than the loss of lung weight, resulting in an increased lung to body weight ratio on postnatal day 21 .

Supplemental oxygen administered to newborn infants with respiratory failure can increase oxidative stress, and lead to lung epithelial cell death. During recovery from sublethal hyperoxia, lung cells may proliferate to replace terminally damaged cells, and failure to impede this proliferation is associated with fibrosis (20). The formation of reactive oxygen species is thought to result in the production of cytokines. The role of cytokines in BPD has been inferred by studies in human infants, which showed that increased levels of cytokines and inflammatory cells in the early stages of infancy were associated with the development of $\operatorname{BPD}(21,22)$. These findings have also been supported by studies of hyperoxic lung injury in animal models $(19,23)$.

Inflammation has been shown to contribute to the development of BPD (24). We found that maternal LPS treatment increased the IFN- $\gamma$, IL- $1 \beta$, and TNF- $\alpha$ expression levels in neonatal rat lungs on postnatal day 7 , and that these influences disappeared by postnatal day 21 . These results are consistent with the findings of Cao et al., who found that the IL-1 $\beta$ and TNF- $\alpha$ mRNA expression in the lungs were significantly greater in LPS-exposed rat pups on postnatal days 6 and 14 than those of control pups and disappeared on postnatal day 21 (25). These data suggest that the effects of maternal LPS exposure on the developing lungs are partially mediated by the indirect actions of circulating cytokines.

In this study, the alterations of body weight and mean linear intercept were similar to those of Yoo et al. study who intracervically injected dams with a single dose of Escherichia coli on gestational day 19 and exposed pups to $85 \% \mathrm{O}_{2}$ for $2 \mathrm{wk}$ (26). They found that intrauterine infection and/or postnatal hyperoxia significantly decreased body weight and increased mean linear intercept compared with pups born to NS-injected dams and reared in RA at $14 \mathrm{~d}$ old. Velten et al. injected mice with LPS $(80 \mu \mathrm{g} / \mathrm{kg})$ on embryonic day 16 and exposed pups to $85 \% \mathrm{O}_{2}$ for $2 \mathrm{wk}$ and subsequently returned to RA (27). They found that lung IL- $1 \beta$ and TNF- $\alpha$ expression were comparable among prenatal LPS/NS- and postnatal hyperoxia/RA-exposed groups on postnatal day 7 and significantly increased in LPS + $\mathrm{O}_{2}$ group compared to NS + RA group on postnatal day 14 . These discrepancies may be due to differences in the route/ dose of endotoxin, rodent strains, and the duration of hyperoxia exposure.

In this study, we found higher IL-10 level in lung tissues in rat pups reared in $\mathrm{O}_{2}$-enriched air. Our investigations focus on the hyperoxia effects on postnatal days 7 and 21 . The increase of inflammatory cytokines could not reach statistical significance may be due to it occurred during the initial period of hyperoxia or may be related to a gradual adaptation to hyperoxia. The anti-inflammatory properties of IL-10 provide protection of the developing lung against hyperoxia injury. Following the initial period of maternal inflammation higher amounts
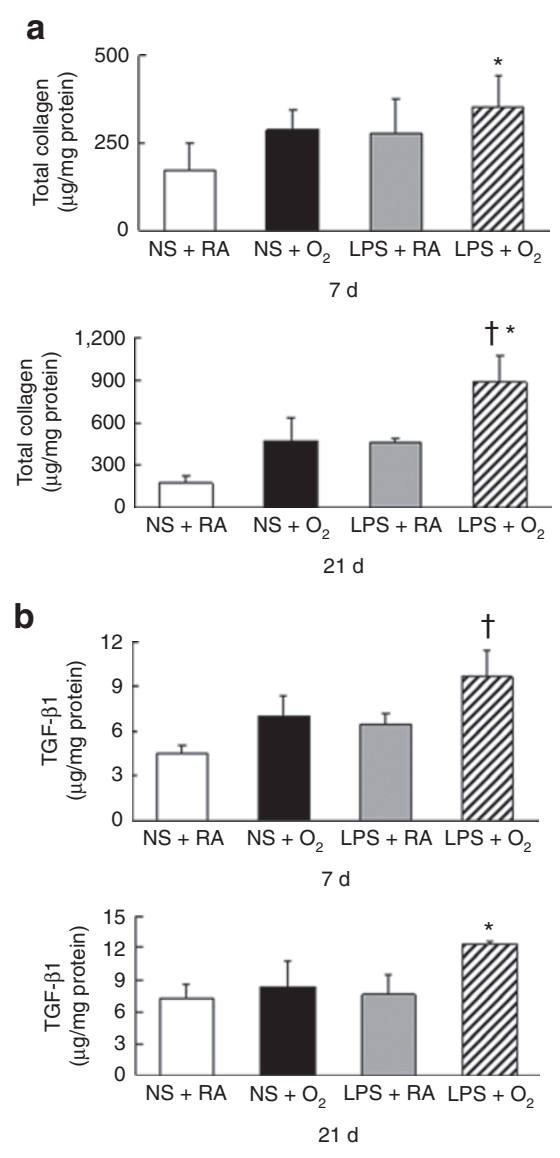

Figure 2. The total collagen content and the levels of TGF- $\beta 1$ in lung tissues on postnatal days 7 and 21. (a) Total collagen content was higher in lung tissues in rat pups born to LPS-treated mothers that were reared in $\mathrm{O}_{2}$-enriched air than rat pups born to normal saline-treated mothers that were reared in room air on postnatal days $7\left(>95 \% \mathrm{O}_{2}{ }^{*}{ }^{*} P<0.05\right)$ and $21\left(60 \% \mathrm{O}_{2}{ }^{\dagger} P<0.001\right)$. The rat pups born to LPS-treated mothers that were reared in $>95 \% \mathrm{O}_{2}$ had significantly higher total collagen content in lung tissues than all the other study groups on postnatal day 21 $\left({ }^{*} P<0.05\right)$. (b) The rat pups born to LPS-treated mothers that were reared in $\mathrm{O}_{2}$-enriched air had significantly higher levels of TGF- $\beta 1$ in lung tissues on postnatal days $7\left(>95 \% \mathrm{O}_{2}\right)$ and $21\left(60 \% \mathrm{O}_{2}\right)$ than rat pups born to normal saline-treated mothers that were reared in room air $\left({ }^{\dagger} P<0.001\right.$, ${ }^{*} P<0.05$, respectively). NS $+R A$, maternal NS treatment with postnatal $\mathrm{RA}$ exposure (open bars); $\mathrm{NS}+\mathrm{O}_{2^{\prime}}$ maternal NS treatment with postnatal $\mathrm{O}_{2}$ exposure (solid bars); LPS + RA, maternal LPS treatment with postnatal RA exposure (gray bars); and LPS $+\mathrm{O}_{2^{\prime}}$ maternal LPS treatment with postnatal $\mathrm{O}_{2}$ exposure (hatched bars). LPS, lipopolysaccharide; NS, normal saline; $\mathrm{O}_{2}$, hyperoxia; $\mathrm{RA}$, room air.

proinflammatory cytokine expressions declined on postnatal day 21, whereas anti-inflammatory cytokine IL-10 expression continued over time.

Pulmonary fibrosis is a common response to various injuries to the lung and is characterized by the excessive production of extracellular matrix, which replaces normal functional parenchyma. Prolonged exposure of neonatal rats to hyperoxic conditions has been reported to increase lung fibrosis in a manner similar to that observed for human BPD $(3,4)$. Collagen is the major extracellular matrix component of the lungs and is vital for maintaining the normal lung architecture (28). The cytokine TGF- $\beta 1$ is a central mediator of various fibrotic disorders, 
a

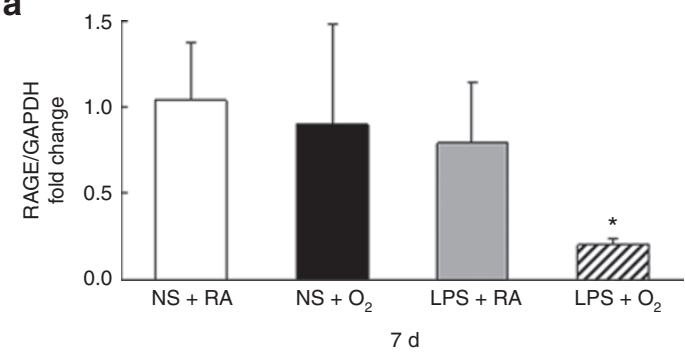

b

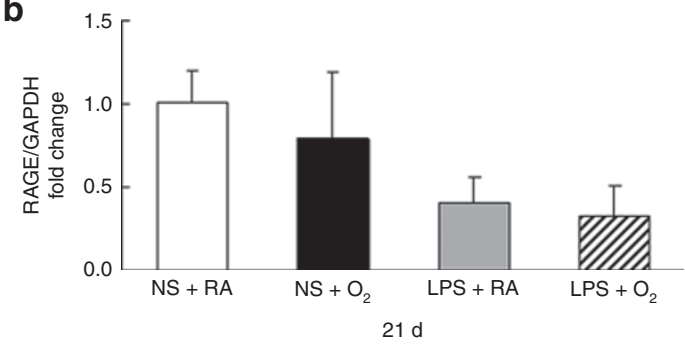

Figure 3. The expression of RAGE mRNA in lung tissues on postnatal days (a) 7 and (b) 21. Total RNA from the lung was extracted, and the RAGE mRNA was quantified using real-time reverse transcription polymerase chain reaction. The expression levels were normalized to GAPDH and are reported as the fold change relative to control rat pups (NS-treated mothers and no postnatal hyperoxia). The level of RAGE mRNA expression was lower in all pups born to LPS-treated mothers than the control rat pups, and the level of RAGE mRNA expression was significantly lower in the rat pups born to LPS-treated mothers that were reared in $\mathrm{O}_{2}$-enriched air on postnatal day 7 compared with the control pups $\left({ }^{*} P<0.05\right)$. NS + RA, maternal NS treatment with postnatal RA exposure (open bars); $\mathrm{NS}+\mathrm{O}_{2^{\prime}}$ maternal NS treatment with postnatal $\mathrm{O}_{2}$ exposure (solid bars); LPS + RA, maternal LPS treatment with postnatal RA exposure (gray bars); and LPS $+\mathrm{O}_{2^{\prime}}$ maternal LPS treatment with postnatal $\mathrm{O}_{2}$ exposure (hatched bars). GAPDH, glyceraldehyde 3-phosphate dehydrogenase; LPS, lipopolysaccharide; NS, normal saline; $\mathrm{O}_{2^{\prime}}$ hyperoxia; RA, room air; RAGE, receptors for advanced glycation end products.

including lung fibrosis and idiopathic pulmonary fibrosis. The activation of TGF- $\beta 1$ expression induces fibroblasts to synthesize and contract the extracellular matrix $(29,30)$. We found that maternal LPS treatment and/or postnatal hyperoxia increased total collagen content and the level of TGF- $\beta 1$ expression in lung tissues, compared with those of the control pups. The correlation between increased TGF- $\beta 1$ expression and increased total collagen content in lung tissues indicates that TGF- $\beta 1$ is involved in systemic maternal inflammation and postnatal hyperoxia-induced lung fibrosis.

The RAGE protein is a member of the immunoglobulin superfamily of cell-surface receptors and is expressed in many cell types. The expression of RAGE is highest in the lung, in which it localizes to the basolateral membranes of well-differentiated alveolar type I cells (31). Membrane RAGE contains an extracellular region composed of one V-type and $2 \mathrm{C}$-type immunoglobulin domains (10). The soluble RAGE isoform contains the same V-type and C-type regions, and it lacks the transmembrane and cytosolic domains. Consequently, sRAGE is found in the extracellular space, and is a competitive, negative regulator of mRAGE activation. Consistent with this phenomenon, we observed similar levels of mRAGE protein expression among all the study groups on postnatal days 7 and 21. In this study, We studied only lung tissue levels of RAGE because of the lack of bronchoalveolar lavage samples and sRAGE present in the bronchoalveolar lavage is an extracellular region of full-length RAGE and the source of RAGE in the alveolar space was primarily alveolar type I epithelial cells (32).

Although its soluble form (sRAGE) acts as a decoy receptor, RAGE is a multiligand receptor known to be involved in fibrotic processes in several organs. Previous studies revealed that RAGE expression produces paradoxical responses in different models of pulmonary fibrosis (33-35). The effect of hyperoxia on RAGE expression has been shown to differ between adult mouse and neonatal rat models $(12,13)$. In our present study, we found that hyperoxia decreased sRAGE expression and increased TGF- $\beta 1$ expression in rat pups, and that mRAGE expression was not altered. These findings are consistent with those for hyperoxia in a neonatal rat model and in vitro studies, which showed that RAGE expression was diminished after the activation of TGF$\beta 1$ expression in alveolar epithelial cells $(13,36)$.

Studies of the responses of RAGE to intratracheal LPS exposure have been inconsistent in adult animal models (37-39). Zhang et al. and Su et al. reported increased RAGE expression in bronchoalveolar lavage fluid, and Ramsgaard et al. reported decreased levels of RAGE expression in lung tissues in LPS-induced lung injury. However, the effect of maternal LPS exposure on the expression of RAGE in the lungs of offspring had not been previously characterized. We found that maternal LPS treatment caused no significant decreases in the expression of RAGE in the lung tissues on rat neonates. We speculated that the small differences in RAGE expression were the results of low LPS dosage and the route of administration (intraperitoneal).

In conclusion, we showed that maternal LPS treatment and postnatal hyperoxia increased total collagen content and TGF$\beta 1$ expression in the lungs of rat neonates during the first 3 postnatal weeks. The development of maternal LPS- and/or postnatal hyperoxia-induced lung fibrosis was associated with decreases in RAGE mRNA and sRAGE protein expression in lung tissues. These results suggest that RAGE may be involved in the pathogenesis of lung fibrosis induced by maternal systemic inflammation and/or postnatal hyperoxia, and that RAGE supplementation strategies may attenuate lung fibrosis. Further investigation of the role of RAGE may provide insights into new treatment strategies in maternal systemic inflammation- and postnatal hyperoxia-induced lung fibrosis.

\section{METHODS}

\section{Animal Model and Experimental Protocol}

Our study was approved by the Animal Care and Use Committee at Taipei Medical University. The time-dated pregnant Sprague-Dawley rats were housed in individual cages, with 12-h light-dark cycling. Laboratory food and water were made available ad libitum. The rats were randomly assigned to the LPS or control treatment subgroups. The LPS treatment strategy consisted of an intraperitoneal injection of LPS $(1 \mathrm{mg} / \mathrm{kg}$ ) from Escherichia coli serotype 0111:B4 (SigmaAldrich, St Louis, MO) in NS, and the control treatment consisted of the intraperitoneal injection of the same volume of NS. The intraperitoneal injections were administered on 20 and $21 \mathrm{~d}$ of gestation. The dose of LPS was based and modified from Cao et al. study as this dose increases lung cytokines in LPS-exposed pups than those of NS-exposed pups $(25,26)$. In initial experiments, we injected 
a
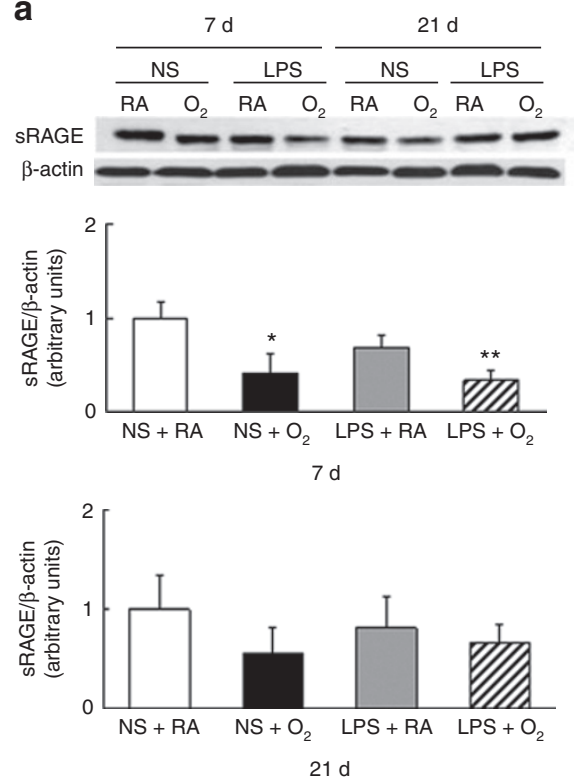

b

\begin{tabular}{|c|c|c|c|c|c|c|c|}
\hline \multicolumn{4}{|c|}{$7 d$} & \multicolumn{4}{|c|}{$21 \mathrm{~d}$} \\
\hline \multicolumn{2}{|c|}{ NS } & \multicolumn{2}{|c|}{ LPS } & \multicolumn{2}{|c|}{ NS } & \multicolumn{2}{|c|}{ LPS } \\
\hline RA & $\mathrm{O}_{2}$ & $\mathrm{RA}$ & $\mathrm{O}_{2}$ & RA & $\mathrm{O}_{2}$ & RA & $\mathrm{O}_{2}$ \\
\hline- & - & - & - & - & - & $\longrightarrow$ & - \\
\hline
\end{tabular}

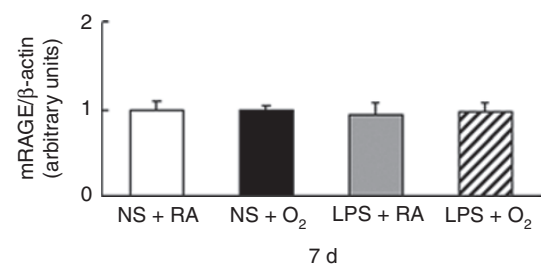

$7 d$

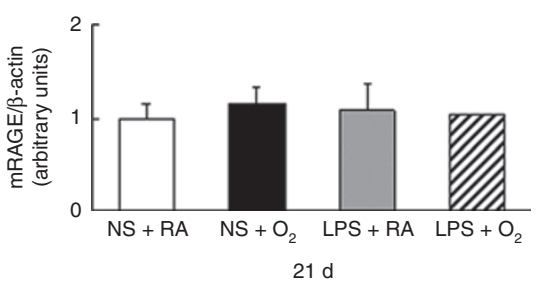

Figure 4. Representative western blotting and scanning densitometry results of the detection and quantification of sRAGE and mRAGE protein expression in lung tissues on postnatal days 7 and 21. (a) The expression of the sRAGE protein was lower in all the rat pups that were reared in hyperoxic conditions on postnatal days 7 and 21 . The level of sRAGE expression was significantly lower on postnatal day 7 in rat pups that were reared in hyperoxic conditions, compared with rat pups that were reared in room air (NS-treated mothers, ${ }^{*} P<0.05$; LPS-treated mothers ${ }^{* *} P<0.01$ ). (b) The levels of mRAGE protein expression were comparable among all the study groups on postnatal days 7 and 21. NS + RA, maternal NS treatment with postnatal RA exposure (open bars); $\mathrm{NS}+\mathrm{O}_{2^{\prime}}$ maternal NS treatment with postnatal $\mathrm{O}_{2}$ exposure (solid bars); LPS + RA, maternal LPS treatment with postnatal RA exposure (gray bars); and LPS $+\mathrm{O}_{2}$, maternal LPS treatment with postnatal $\mathrm{O}_{2}$ exposure (hatched bars). LPS, lipopolysaccharide; $\mathrm{NS}$, normal saline; $\mathrm{O}_{2}$, hyperoxia; $\mathrm{RA}$, room air; RAGE, receptors for advanced glycation end products.

$2.5 \mathrm{mg} / \mathrm{kg}$ of LPS as this dose increases lung inflammation in LPSexposed pups. However, this dose of LPS resulted in $50 \%$ mortality of dams and $100 \%$ fatality of fetuses. Therefore, we used $1.0 \mathrm{mg} / \mathrm{kg}$ body weight of LPS on days 20 and 21 of gestation in this study.

The rat dams were allowed to deliver vaginally at term. Within $12 \mathrm{~h}$ of birth, litters from each treatment were pooled and randomly redistributed to the newly delivered mothers, and then the pups were randomly assigned to the RA and $\mathrm{O}_{2}$ treatment subgroups, creating four study groups as follows: $\mathrm{NS}+\mathrm{RA}$, NS $+\mathrm{O}_{2}$, LPS $+\mathrm{RA}$, and $\mathrm{LPS}+\mathrm{O}_{2}$ (Figure 6). The pups in the $\mathrm{O}_{2}$ treatment subgroups were reared in an atmosphere containing $>95 \% \mathrm{O}_{2}$ during postnatal days 1 to 7 and $60 \% \mathrm{O}_{2}$ during postnatal days 8 to 21 . The pups in the RA control subgroups were reared in normal RA for $21 \mathrm{~d}$.

The nursing mothers were rotated between the $\mathrm{O}_{2}$ treatment and RA control litters every $24 \mathrm{~h}$ to avoid oxygen toxicity in the mothers and eliminate maternal effects between the treatment subgroups. The oxygen rich atmosphere was maintained in a transparent $40 \times 50 \times 60 \mathrm{~cm}$ plexiglass chamber that received $\mathrm{O}_{2}$ continuously at 4 l/min. The oxygen levels were monitored using a Proox Model 110 monitor (BioSpherix, Redfield, NY). Pups from each treatment group were killed with intravenous injections of pentobarbital $(100 \mathrm{mg} / \mathrm{kg})$ on postnatal days 7 and 21, and body and lung weights were recorded. Immediately after death, the left lung was ligated and the right lung was fixed by tracheal instillation of $10 \%$ buffered formalin at a pressure of $25 \mathrm{~cm} \mathrm{H} O$ for $10 \mathrm{~min}$. Fixation was continued by placing the lungs in buffered formalin for $24 \mathrm{~h}$.

\section{Histology}

The lungs were placed in $4 \%$ paraformaldehyde and washed in phosphate-buffered saline and serially dehydrated in increasing concentrations of ethanol before being embedded in paraffin. Two pups per litter were used for histological analyses. Five micrometer tissue sections are stained with hematoxylin and eosin and examined by light microscopy. Mean linear intercept, an indicator of mean alveolar diameter, was assessed in 10 nonoverlapping fields at a $\times 200$ magnification in one hematoxylin and eosin section for each animal.

\section{Cytokine and Chemokine Levels}

Approximately $100 \mathrm{mg}$ of lung tissue from each pup was homogenized with Procarta lysis buffer (Affymetrix, Santa Clara, CA) according to the manufacturer's instructions. The cell extracts were centrifuged, and levels of IL-1 $\beta$, TNF- $\alpha$, MIP-2, IL-10, IFN- $\gamma$, and RANTES in the supernatants were determined using the Bio-Plex multiplex assay system (Bio-Rad, Hercules, CA) and the Procarta immunoassay kit (Affymetrix).

\section{Measurement of Total Collagen}

The level of lung collagen was determined by assaying the total soluble collagen protein using the Sircol Collagen Assay Kit (Biocolor, Newton Abbey, UK) according to the manufacturer's instructions. This method measures newly synthesized collagen that has not been extensively cross-linked. Briefly, lungs were homogenized in $5 \mathrm{ml}$ of $0.5 \mathrm{~mol} / \mathrm{l}$ acetic acid containing $1 \mathrm{mg}$ of pepsin (SigmaAldrich) per $10 \mathrm{mg}$ of tissue. Each sample was incubated for $24 \mathrm{~h}$ at $4{ }^{\circ} \mathrm{C}$ with stirring, before centrifugation. For soluble collagen detection, $1 \mathrm{ml}$ of Sircol dye reagent, which binds specifically to collagen, was added to $100 \mu \mathrm{l}$ of supernatant from each sample, and mixed for $30 \mathrm{~min}$, before centrifugation. The pellets were resuspended in $1 \mathrm{ml}$ of alkali reagent $(0.5 \mathrm{~mol} / \mathrm{l} \mathrm{NaOH})$, and the optical density was evaluated at $540 \mathrm{~nm}$ using a spectrophotometer. The concentration of collagen in each sample was extrapolated from a standard curve that was constructed using standard solutions provided by the kit manufacturer.

\section{Transforming Growth Factor- $\beta 1$ Levels}

The level of TGF- $\beta 1$ expression in lung tissues was determined using the Biosource enzyme-linked immunosorbent assay kit (Invitrogen, Carlsbad, CA). Lung tissue homogenates were prepared, and the concentration of TGF- $\beta 1$ in the supernatants was measured according to the manufacturer's instructions.

\section{RNA Isolation and Real-Time Reverse-Transcriptase PCR}

The expression of RAGE mRNA was quantified using real-time reverse transcription PCR. Total RNA was extracted using the Trizol reagent (Invitrogen). The cDNA was synthesized using the 
NS

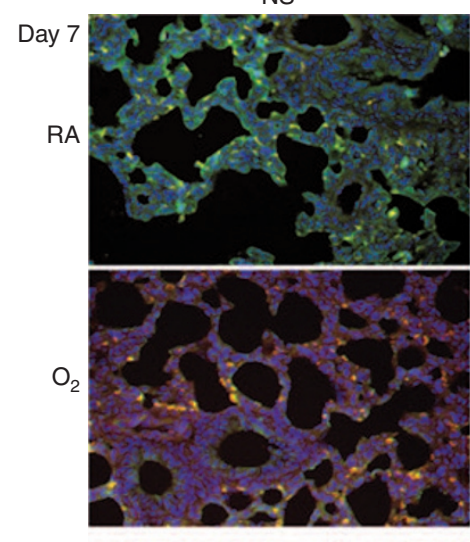

NS

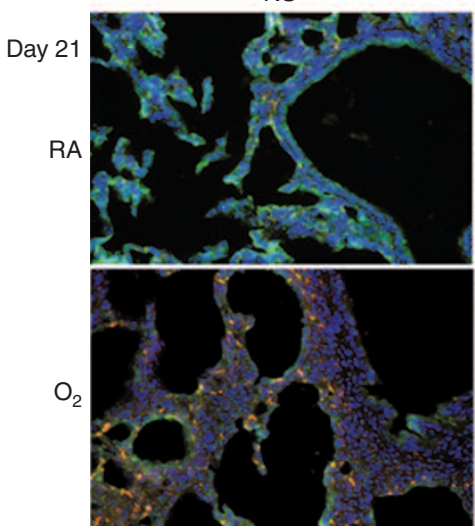

LPS

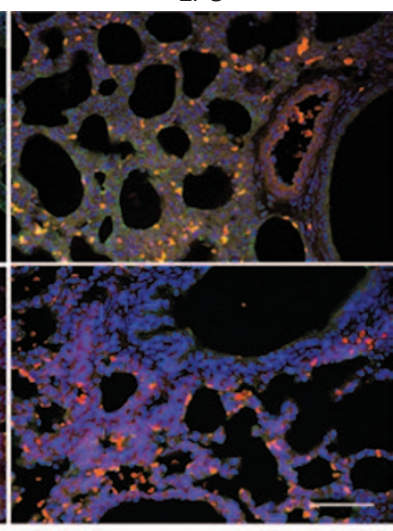

LPS

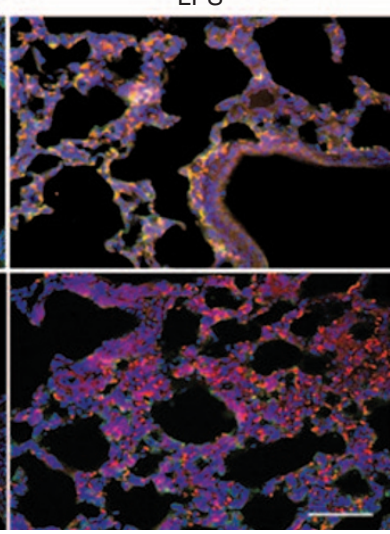

Figure 5. Immunofluorescence of RAGE and collagen expression in lung tissues on postnatal days 7 and 21. Top: immunofluorescence staining of pups killed on postnatal day 7. Bottom: immunofluorescence staining of pups killed on postnatal day 21 ( $7 \mathrm{~d}$ in $>95 \% \mathrm{O}_{2}$ followed by $60 \% \mathrm{O}_{2}$ for 14 d). Immunofluorescence staining for RAGE (green) in airway epithelial cells and endothelial cells and collagen (red) in interstitium and DAPI (blue) in nucleoli. The RAGE immunofluorescence was downregulated and collagen immunofluorescence was upregulated after maternal LPS and/or postnatal hyperoxia exposure. Collagen fluorescence was markedly increased after maternal LPS and postnatal hyperoxia exposure on postnatal days 7 and 21. LPS, lipopolysaccharide; NS, normal saline; $\mathrm{O}_{2}$, hyperoxia; RA, room air; RAGE, receptors for advanced glycation end products.

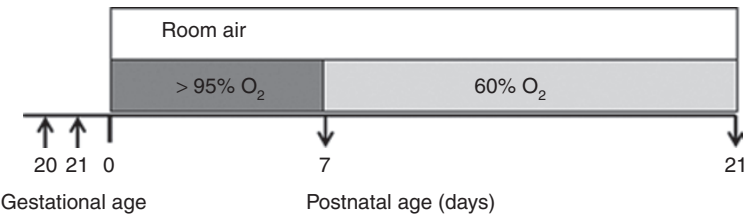

Figure 6. Diagrammatic representation of the experimental design showing the study timeline and the rat pup treatment groups. $\uparrow$ indicates maternal LPS or saline injection. $\downarrow$ indicates time of killing.

First-Strand cDNA Synthesis Kit (GE Healthcare, Waukesha, WI). The primer sequences used for RAGE quantification were 5'-AGCTTCAGTCTGGGCCTTC-3' and 5'-CAGCTGAATGCCC TCTGG-3'. The primer sequences used for the glyceraldehyde 3-phosphate dehydrogenase (GAPDH) control mRNA were $5^{\prime}$-CT CCCTCAAGATTGTCAGCAA-3' and 5'-GTCAGATCCACAACG GATACATT-3'. The mRNA levels were quantified using the comparative $\mathrm{C}_{\mathrm{T}}\left(\Delta \Delta \mathrm{C}_{\mathrm{T}}\right)$ method, in which $\mathrm{C}_{\mathrm{T}}$ is the threshold cycle number (the minimum number of cycles needed before the product can be detected). The arithmetic formula for the $\Delta \Delta \mathrm{C}_{\mathrm{T}}$ method is the difference in threshold cycles for a target and an endogenous reference (GAPDH). The amount of target RNA normalized to an endogenous reference and relative to a calibration normalized to an endogenous reference was given by $2^{-\Delta \Delta} \mathrm{C}_{\mathrm{T}}$.

\section{Western Blot Analysis of RAGE}

The expression of RAGE was also analyzed by western blotting. Lung tissues were homogenized in ice-cold buffer containing $50 \mathrm{mmol} / \mathrm{l}$ potassium phosphate, $0.3 \mathrm{~mol} / \mathrm{l}$ potassium bromide, $3 \mathrm{mmol} / \mathrm{l}$ diethylenetriamine pentaacetic acid, and $0.5 \mathrm{mmol} / \mathrm{l}$ phenylmethyl sulfonylfluoride at $\mathrm{pH}$ 7.4. The samples were sonicated and centrifuged at $20,000 \mathrm{~g}$ for $20 \mathrm{~min}$ at $4{ }^{\circ} \mathrm{C}$. The supernatant comprised the soluble fraction and contained the sRAGE protein. The pellet was resuspended in CHAPS detergent, vortexed, sonicated, and incubated at 4 ${ }^{\circ} \mathrm{C}$ overnight with gentle shaking. The samples were incubated without shaking for $2 \mathrm{~h}$ at $4{ }^{\circ} \mathrm{C}$ and centrifuged at $20,000 \mathrm{~g}$ for $20 \mathrm{~min}$ at 4 ${ }^{\circ} \mathrm{C}$. The supernatant comprised the soluble membrane fraction and contained the mRAGE protein. The western blot analysis was performed as described previously (13).

\section{Immunofluorescence}

Immunofluorescence staining was performed on the paraffin sections. After the routine deparaffinization, heat-induced epitope retrieval was done by immersing slides in $0.01 \mathrm{~mol} / \mathrm{l}$ sodium citrate buffer ( $\mathrm{pH}$ 6.0). Block endogenous peroxidase activity and nonspecific binding of antibody, sections were first preincubated for $1 \mathrm{~h}$ at room temperature in $0.1 \mathrm{~mol} / \mathrm{l}$ phosphate-buffered saline containing $10 \%$ normal goat serum and $0.3 \% \mathrm{H}_{2} \mathrm{O}_{2}$ before being incubated for overnight at $4{ }^{\circ} \mathrm{C}$ with rabbit anti-RAGE 1:25 and mouse anti-collagen I 1:100 (Abcam, Boston, MA). The fluorochrome-conjugated secondary antibodies used were Fluorescein (FITC)-AffiniPure goat anti-rabbit IgG $(\mathrm{H}+\mathrm{L})$ and Rhodamine (TRITC)-AffiniPure goat anti-mouse IgG $(\mathrm{H}+\mathrm{L}) \quad(1: 200$, Jackson ImmunoResearch Labotories, West Grove, PA). Nuclei were detected with DAPI (4',6-diaminidino-2-phenylindole, 1:1,000; Sigma, St Louis, MO). The sections were then washed with phosphate-buffered saline, mounted and examined under a fluorescence microscope.

\section{Statistical Analysis}

The data are presented as means \pm SD. Statistical analyses were performed by two-way ANOVA with Bonferroni post hoc for multiple-group comparisons. Differences were considered statistically significant when $P<0.05$.

\section{STATEMENT OF FINANCIAL SUPPORT}

This work was supported by grants from Taipei Medical University Hospital (101TMU-TMUH-10) and the National Science Council of Taiwan (NSC 1002314-B-038-020).

Disclosure: The authors have declared that no competing interests exist.

\section{REFERENCES}

1. Abman SH. Bronchopulmonary dysplasia: "a vascular hypothesis". Am J Respir Crit Care Med 2001;164(10 Pt 1):1755-6.

2. Jobe AH, Bancalari E. Bronchopulmonary dysplasia. Am J Respir Crit Care Med 2001;163:1723-9.

3. Manji JS, O'Kelly CJ, Leung WI, Olson DM. Timing of hyperoxic exposure during alveolarization influences damage mediated by leukotrienes. Am J Physiol Lung Cell Mol Physiol 2001;281:L799-806.

4. Chen CM, Wang LF, Chou HC, Lang YD, Lai YP. Up-regulation of connective tissue growth factor in hyperoxia-induced lung fibrosis. Pediatr Res 2007;62:128-33.

5. Welty SE. Is there a role for antioxidant therapy in bronchopulmonary dysplasia? J Nutr 2001;131:947S-50S.

6. Andrews WW, Goldenberg RL, Faye-Petersen O, Cliver S, Goepfert AR, Hauth JC. The Alabama Preterm Birth study: polymorphonuclear and mononuclear cell placental infiltrations, other markers of inflammation, and outcomes in 23- to 32-week preterm newborn infants. Am J Obstet Gynecol 2006;195:803-8.

7. Speer CP. Inflammation and bronchopulmonary dysplasia: a continuing story. Semin Fetal Neonatal Med 2006;11:354-62. 
8. Choi CW, Kim BI, Hong JS, Kim EK, Kim HS, Choi JH. Bronchopulmonary dysplasia in a rat model induced by intra-amniotic inflammation and postnatal hyperoxia: morphometric aspects. Pediatr Res 2009;65:323-7.

9. Velten M, Heyob KM, Rogers LK, Welty SE. Deficits in lung alveolarization and function after systemic maternal inflammation and neonatal hyperoxia exposure. J Appl Physiol 2010;108:1347-56.

10. Buckley ST, Ehrhardt C. The receptor for advanced glycation end products (RAGE) and the lung. J Biomed Biotechnol 2010;2010:917108.

11. Reynolds PR, Kasteler SD, Cosio MG, Sturrock A, Huecksteadt T, Hoidal JR. RAGE: developmental expression and positive feedback regulation by Egr-1 during cigarette smoke exposure in pulmonary epithelial cells. Am J Physiol Lung Cell Mol Physiol 2008;294:L1094-101.

12. Reynolds PR, Schmitt RE, Kasteler SD, et al. Receptors for advanced glycation end-products targeting protect against hyperoxia-induced lung injury in mice. Am J Respir Cell Mol Biol 2010;42:545-51.

13. Lizotte PP, Hanford LE, Enghild JJ, Nozik-Grayck E, Giles BL, Oury TD. Developmental expression of the receptor for advanced glycation endproducts (RAGE) and its response to hyperoxia in the neonatal rat lung. BMC Dev Biol 2007;7:15.

14. Kenyon NJ, Ward RW, McGrew G, Last JA. TGF-betal causes airway fibrosis and increased collagen I and III mRNA in mice. Thorax 2003;58:772-7.

15. Dasgupta C, Sakurai R, Wang Y, et al. Hyperoxia-induced neonatal rat lung injury involves activation of TGF-\{beta $\}$ and Wnt signaling and is protected by rosiglitazone. Am J Physiol Lung Cell Mol Physiol 2009;296:L1031-41.

16. Li Z, Choo-Wing R, Sun H, et al. A potential role of the JNK pathway in hyperoxia-induced cell death, myofibroblast transdifferentiation and TGFß1-mediated injury in the developing murine lung. BMC Cell Biol 2011;12:54.

17. Ruiz V, Ordóñez RM, Berumen J, et al. Unbalanced collagenases/TIMP-1 expression and epithelial apoptosis in experimental lung fibrosis. Am J Physiol Lung Cell Mol Physiol 2003;285:L1026-36.

18. Veness-Meehan KA, Bottone FG Jr, Stiles AD. Effects of retinoic acid on airspace development and lung collagen in hyperoxia-exposed newborn rats. Pediatr Res 2000;48:434-44.

19. Ozer EA, Kumral A, Ozer E, et al. Effects of erythropoietin on hyperoxic lung injury in neonatal rats. Pediatr Res 2005;58:38-41.

20. Lee J, Reddy R, Barsky L, Weinberg K, Driscoll B. Contribution of proliferation and DNA damage repair to alveolar epithelial type 2 cell recovery from hyperoxia. Am J Physiol Lung Cell Mol Physiol 2006;290:L685-94.

21. Wang H, Oei J, Lui K, Henry R. Interleukin-16 in tracheal aspirate fluids of newborn infants. Early Hum Dev 2002;67:79-86.

22. Groneck P, Schmale J, Soditt V, Stützer H, Götze-Speer B, Speer CP. Bronchoalveolar inflammation following airway infection in preterm infants with chronic lung disease. Pediatr Pulmonol 2001;31:331-8.

23. James ML, Ross AC, Bulger A, Philips JB 3rd, Ambalavanan N. Vitamin A and retinoic acid act synergistically to increase lung retinyl esters during normoxia and reduce hyperoxic lung injury in newborn mice. Pediatr Res 2010;67:591-7.

24. Kim DH, Choi CW, Kim EK, et al. Association of increased pulmonary interleukin-6 with the priming effect of intra-amniotic lipopolysaccharide on hyperoxic lung injury in a rat model of bronchopulmonary dysplasia. Neonatology 2010;98:23-32.

25. Cao L, Wang J, Tseu I, Luo D, Post M. Maternal exposure to endotoxin delays alveolarization during postnatal rat lung development. Am J Physiol Lung Cell Mol Physiol 2009;296:L726-37.

26. Yoo HS, Chang YS, Kim JK, et al. Antenatal betamethasone attenuates intrauterine infection-aggravated hyperoxia-induced lung injury in neonatal rats. Pediatr Res 2013;73:726-33.

27. Velten M, Britt RD Jr, Heyob KM, et al. Prenatal inflammation exacerbates hyperoxia-induced functional and structural changes in adult mice. Am J Physiol Regul Integr Comp Physiol 2012;303:R279-90.

28. Suki B, Ito S, Stamenovic D, Lutchen KR, Ingenito EP. Biomechanics of the lung parenchyma: critical roles of collagen and mechanical forces. J Appl Physiol 2005;98:1892-9.

29. Liu RM, Vayalil PK, Ballinger C, et al. Transforming growth factor $B$ suppresses glutamate-cysteine ligase gene expression and induces oxidative stress in a lung fibrosis model. Free Radic Biol Med 2012;53:554-63.

30. Reilkoff RA, Peng H, Murray LA, et al. Semaphorin $7 \mathrm{a}+$ regulatory T cells are associated with progressive idiopathic pulmonary fibrosis and are implicated in transforming growth factor- $\beta 1$-induced pulmonary fibrosis. Am J Respir Crit Care Med 2013;187:180-8.

31. Schmidt AM, Yan SD, Yan SF, Stern DM. The multiligand receptor RAGE as a progression factor amplifying immune and inflammatory responses. J Clin Invest 2001;108:949-55.

32. Uchida T, Shirasawa M, Ware LB, et al. Receptor for advanced glycation end-products is a marker of type I cell injury in acute lung injury. Am J Respir Crit Care Med 2006;173:1008-15.

33. Englert JM, Kliment CR, Ramsgaard L, et al. Paradoxical function for the receptor for advanced glycation end products in mouse models of pulmonary fibrosis. Int J Clin Exp Pathol 2011;4:241-54.

34. Queisser MA, Kouri FM, Königshoff M, et al. Loss of RAGE in pulmonary fibrosis: molecular relations to functional changes in pulmonary cell types. Am J Respir Cell Mol Biol 2008;39:337-45.

35. He M, Kubo H, Ishizawa K, et al. The role of the receptor for advanced glycation end-products in lung fibrosis. Am J Physiol Lung Cell Mol Physiol 2007;293:L1427-36.

36. Buckley ST, Medina C, Kasper M, Ehrhardt C. Interplay between RAGE, $\mathrm{CD} 44$, and focal adhesion molecules in epithelial-mesenchymal transition of alveolar epithelial cells. Am J Physiol Lung Cell Mol Physiol 2011;300:L548-59.

37. Ramsgaard L, Englert JM, Manni ML, et al. Lack of the receptor for advanced glycation end-products attenuates E. coli pneumonia in mice. PLoS ONE 2011;6:e20132.

38. Su X, Looney MR, Gupta N, Matthay MA. Receptor for advanced glycation end-products (RAGE) is an indicator of direct lung injury in models of experimental lung injury. Am J Physiol Lung Cell Mol Physiol 2009;297:L1-5.

39. Zhang H, Tasaka S, Shiraishi Y, et al. Role of soluble receptor for advanced glycation end products on endotoxin-induced lung injury. Am J Respir Crit Care Med 2008;178:356-62. 